ORIGINAL ARTICLE

AFRICAN JOURNAL OF CLINICAL AND EXPERIMENTAL MICROBIOLOGY SEPTEMBER 2013 ISBN 1595-689X VOL14 No.3

AJCEM/1322

http://www.ajol.info/journals/ajcem

COPYRIGHT 2013

AFR. J. CLN. EXPER. MICROBIOL. 14(3): 184-189. http://dx.doi.org/10.4314/ajcem.v14i3.12

\title{
THE RELATIONSHIP BETWEEN PERCEPTION AND PREVALENCE OF FAECAL-ORALLY TRANSMITTED PARASITIC INFECTIONS AMONG SCHOOL CHILDREN IN A RURAL COMMUNITY IN CAMEROON
}

\author{
Kamga, H. L. F. ${ }^{~}{ }^{*}$, Nde, P. F. ${ }^{4}$, Fomumbod, S. A. ${ }^{2}$, Nguemaim, F ${ }^{1}$,Kwenti, T. E. ${ }^{,}$, Nsagha, D. S. ${ }^{4}$, Assob, N. J. C. ${ }^{3}$, Njunda, AL
}

${ }^{1}$ Department of Medical Laboratory Science, Faculty of Health Sciences, University of Bamenda, ${ }^{2}$ Department Zoology, Faculty of Science, University of Buea; ${ }^{3}$ Medicine Programme, Faculty of Health Sciences, University of Buea; ${ }^{4}$ Department of Public Health, Faculty of Health Sciences, University of Buea; ${ }^{5}$ Department of Medical Laboratory Science, Faculty of Health Sciences, University of Buea.

* Correspondence: Henri Lucien Fouamno Kamga, Department of Medical Laboratory Science, Faculty of Health Sciences, University of Bamenda, Republic of Cameroon. E-mail: henrikamga2002@yahoo.fr

\begin{abstract}
Background: Faecal-orally transmitted parasites are those which are spread through faecal contamination of food and drinks. Infections with these parasites are responsible for high morbidity and mortality, especially in children in developing countries.

Objective: This study was carried out to determine school children's perception of faecal-orally transmitted parasitic infections and the relationship between that perception and the prevalence of the infections.

Methods: Data were collected through questionnaires and laboratory analysis of stool samples. The study was conducted in two phases. In phase 1 questionnaires were administered to determine children's knowledge on the cause, risk behaviours and prevention of the faecal-orally parasite infections. Stool specimens were analyzed using the formol-ether concentration technique. Health education was utilized in the experimental village, but not the control. Phase 2 was conducted six months later during which questionnaires were distributed and stool samples analyzed from both villages.

Results: A total of 370 children were enrolled in this intervention study, out of which 208 were from Kake II (experimental arm) and 162 from Barombi-kang (control arm). At Kake II there was a significant increase in awareness in relation to the source of infection $(9.5 \%$ vs. $62.5 \%, \mathrm{P}<0.001)$, risk behaviour $(12.4 \%$ vs. $83.7, \mathrm{P}<0.001)$ and prevention $(17.9 \%$ vs. $84.8 \%$, $\mathrm{P}<0.001)$ between the first and second phase of the study, followed by a significant change in the prevalence of Ascaris lumbricoides $(24.9 \%$ vs. $3.4 \%$, $\mathrm{P}<0.001)$, Entamoeba coli $(12.9 \%$ vs. $6.5 \%, \mathrm{P}<0.001)$, Trichuris trichiura $(22.4 \%$ vs. $12.5 \%, \mathrm{P}=0.004)$ and Entamoeba histolytica $(6.0 \%$ vs. $1.9 \%, P=0.035)$. In Barombi-kang the change in the awareness was not significant $(P>0.1)$ and there was no significant change in the prevalence of any of the faecal-orally transmitted parasites detected. The relationship between the perception and the prevalence of feacal orally transmitted parasitic infections showed a strong negative correlation ( $r$ dispersed between -0.97 and -99$)$

Conclusion: Health education applied in the experimental village was responsible for the changed perception of infection by children and consequently for the reduction of infestation rate. Good perception of the infection was inversely proportional to its prevalence. Therefore, health education through the framework of school proved to be an effective control method for faecalorally transmitted parasite infections. We recommend this inexpensive method to be adopted as a national policy in developing countries, especially in rural communities.
\end{abstract}

Key Words: Perception and prevalence, Faecal-orally transmitted parasitic infections, School children, Cameroon

\section{INTRODUCTION}

Parasitic infections, caused by intestinal parasites, are among the most prevalent infections in humans in developing countries and are responsible for considerable morbidity and morality in endemic countries. Most of them are transmitted by the faecaloral route. In general, situations involving close human-human contact and unhygienic conditions promote transmission (1). These infections are globally endemic and have been described as constituting the greatest single worldwide cause of illness and disease (2). They are associated with poor hygiene and lack of access to safe water. Several factors including temperature, humidity, natural disasters, socioeconomic status and customary nutrition of people play a role in the distribution of these parasites (3). Food handlers also play an important role in their transmission $(4,5)$.

The most common of these faecal-orally transmitted parasites are the soil transmitted helminth (STH) which include Ascaris lumbricoides, Trichuris trichiura and the hookworms (Necator americanus and 
Ancylostoma duodenale), and in developing countries it is common that children are parasitized with more than one species at the same time, with resultant impairments in physical, intellectual, and cognitive development, if heavy infections are left untreated $(6,7)$. These infections rarely cause death. Instead, the burden of disease is related less to mortality than to the chronic and insidious effects on health and nutritional status of the host (7).

Like the majority of the parasitic diseases, these infections are influenced by human behaviour especially their hygienic practices, and also failure to take advantage of available screening services or comply with treatment (8). Control measures against intestinal parasites include chemotherapy and sanitation. Chemotherapy is an effective short term measure while sanitation is effective long term control measure (9). Control in school age children delivered through school system is the main intervention strategy in a community (10). Morbidity and worm load have been found to decrease considerably where health care has been efficiently integrated with education programmes (11).

In Cameroon, intestinal parasite infections are recognised by the ministry of public health to be an important public health problem ranking second to malaria (12). Soil transmitted helminths are highly endemic in the south west region of the country, particularly in rural areas where sanitary conditions are poor $(13,14)$. Control typically focuses on periodic antihelminthic treatments targeted at specific risk groups, for example; school children. Re-infection in endemic areas is continuous $(15,16)$. Chemotherapy remains the main means of managing morbidity from faecal-orally transmitted parasites. However, the prevention of re-infection and the reduction in the incidence of infection require that population have a good perception of the disease as a health problem. This study therefore aims at determining school children's perception of faecal-orally transmitted parasitic infections and evaluates the relationship between that perception and infection prevalence.

\section{MATERIALS AND METHODS}

Ten villages in the Kumba district in the South West Region of Cameroon were grouped in pairs. Each pair was made of 2 rural communities sharing the same social, geographical and climatic features. The pair comprising Kake II and Barombi-Kang was randomly selected among five. For the selection of experimental and controls arm, a coin was tossed and the decision taken was based on the observed side. An intervention study was conducted in the primary schools of the selected villages (Kake II and Barombi-kang). They are separated by a distance of $30 \mathrm{Km}$. The former village served as the experimental arm, whilst the latter served as the control arm. The two villages are typical African rural communities. There is no pipe-borne water, electricity, or drainage system. Each of the villages has a government owned primary school, but no secondary school. The inhabitants are farmers practicing peasant farming and petty trading.

Prior to the start of this study, permission was sought from the school authorities and parents were informed about the purpose, objectives and benefits of the study, as their involvement was a key factor for its success. They were made to understand that it was not a school obligation to take part in the study, neither was it a prerequisite for accessing publicly available health facilities. Written informed parental assent forms were distributed one week prior to the beginning of data collection. An ethical clearance was obtained from the Institutional Review Board (IRB) of the Regional Delegation of Health (Ref.R11/MPH/SWP/RDPH/FP$\mathrm{R} / 5341 / 94)$.

\section{Phases of the study}

The study was conducted in two phases.

\section{Phase 1}

Data were obtained from questionnaire and laboratory analysis of stool samples. School children were administered questionnaires structured to provide information on personal bio data (name, age, sex) and their awareness toward faecal-orally transmitted parasites. Children questionnaires were prepared and distributed through the head masters of the schools and the teachers with the aim to test their perception of the source of infection, the prevention measures and the treatment seeking behaviour. Questionnaires were returned through the same channel. Stool samples were collected in well labelled $50 \mathrm{ml}$ screw-cap vials and then transported to the Kumba district hospital laboratory. Samples were collected from volunteer pupils aged between 5-15 years. Stool specimens were analyzed using the formol-ether concentration technique as already described elsewhere (17). All slides were read within $24 \mathrm{~h}$ of preparation to avoid the degeneration of Ancylostoma sp. eggs. Following sample collection, health education was given to the pupils in Kake II school (experimental arm), and it was aimed at promoting and reinforcing health behaviour with particular reference to the need to encourage aspects of personal hygiene relevant to the control of faecal-orally transmitted parasitic infections. Focus group discussions were held in the school using pictorial cards. Basic messages communicated were: what faecal-orally transmitted parasites are, how the infections are acquired, what the signs and symptoms are, what can be done to prevent these parasites, and the importance of visiting the health centre for treatment. In Barombi-Kang (control arm), only the baseline data were collected without any health education. 
Phase II

This phase was conducted 6 months after the end of the first intervention. It consisted of administering the same pre-designed and pre-tested questionnaire to assess children's perception and collecting stool samples for laboratory analysis. For ethical reasons, pupils in the control village (Barombi-kang) received health education at the end of the sample collection.

\section{Data Management and Analysis}

Data was entered using Epi-Info 6.04 (CDC) and analyzed using the Statistical Package for Social Sciences version 17.0 (SPSS Inc. 2008). The Chi-Square test was used to compare proportions before and after the health education intervention at significant level of 0.05 .

\section{RESULTS}

Table 1 shows the perception of faecal-oral parasite infection in Kake II (experimental arm) and BarombiKang (control arm) before and after health education intervention. Awareness levels in the two villages was low during the first intervention (dispersing between $9.5 \%$ and $18.4 \%$ ). In the second phase, the level of awareness increased significantly in Kake II with respect to the source of infection $(9.5 \%$ vs. $62.5 \%$, $\mathrm{P}<0.001)$, risk behaviour $(12.4 \%$ vs. $83.7 \%, \mathrm{P}<0.001)$ and prevention and/or treatment $(17.9 \%$ vs. $84.6 \%$, $\mathrm{P}<0.001$ ) of faecal-oral parasite infection. There was no significant increase in the control arm with respect to the source of infection $(6.7 \%$ vs. $10.1 \%, \mathrm{P}=0.271)$, risk behaviour $(17.2 \%$ vs. $20.8 \%, \mathrm{P}=0.397)$ nor prevention and/or treatment $(18.49 \%$ vs. $25.6 \%, \mathrm{P}=0.115)$.

TABLE 1: CHILDREN'S PERCEPTION OF FAECAL-ORAL PARASITES INFECTION IN KAKE II (EXPERIMENTAL ARM) AND BAROMBI-KANG (CONTROL ARM) BEFORE AND AFTER HEALTH EDUCATION (HE) INTERVENTION

\begin{tabular}{|c|c|c|c|c|}
\hline \multirow{2}{*}{ Perception } & \multicolumn{2}{|c|}{$\begin{array}{l}\text { Number }(\%)^{*} \text { of pupils with good } \\
\text { knowledge in Kake II } \\
\text { (experimental arm) }\end{array}$} & \multicolumn{2}{|c|}{$\begin{array}{l}\text { Number }(\%)^{*} \text { of pupils with good knowledge in } \\
\text { Barombi-kang } \\
\text { (control arm) }\end{array}$} \\
\hline & $\begin{array}{l}\text { Before health } \\
\text { education }\end{array}$ & $\begin{array}{ll}\begin{array}{l}\text { After } \\
\text { education }\end{array} & \text { health } \\
\end{array}$ & $\begin{array}{ll}\begin{array}{l}\text { Phase } \\
\text { intervention }\end{array} & 1 \\
\end{array}$ & Phase 2 intervention \\
\hline Source of infection & $19(9.5)$ & $131(62.5)$ & $11(6.7)$ & $17(10.1)$ \\
\hline Risk behaviour & 25 (12.4) & 174 (83.7) & $28(17.2)$ & $35(20.8)$ \\
\hline $\begin{array}{l}\text { Mode of prevention } \\
\text { and/or treatment }\end{array}$ & $36(17.9)$ & $178(84.6)$ & $30(18.4)$ & $41(25.6)$ \\
\hline
\end{tabular}

$\mathrm{P}<0.001$ in Kake II (experimental arm); P>0.1 in Barombi-Kang (control arm)

*Percentage is based on the number of respondents

TABLE 2: PREVALENCE OF DIFFERENT SPECIES OF FAECAL-ORALLY TRANSMITTED PARASITES IN KAKE II (EXPERIMENTAL ARM) AND BAROMBI-KANG BEFORE (CONTROL ARM) BEFORE AND AFTER HEALTH EDUCATION INTERVENTION

\begin{tabular}{|l|l|l|l|l|}
\hline \multirow{2}{*}{ Parasite species } & \multicolumn{2}{|l|}{$\begin{array}{l}\text { Number (\%) of infected stool samples in } \\
\text { Kake II (experimental arm) }\end{array}$} & \multicolumn{2}{l|}{$\begin{array}{l}\text { Number (\%) of infected stool samples in } \\
\text { Barombi-Kang (control arm) }\end{array}$} \\
\cline { 2 - 5 } & Before health education & $\begin{array}{l}\text { After } \\
\text { education }\end{array}$ & health & $\begin{array}{l}\text { Phase1 } \\
\text { intervention }\end{array}$ \\
\hline A. lumbricoides* & $50(24.9)$ & $7(3.4)$ & $28(17.3)$ & $29(18.1)$ \\
\hline T. trichiura* & $47(22.4)$ & $26(12.5)$ & $18(11.1)$ & $16(0.1)$ \\
\hline E. vermicularis & $3(1.5)$ & $4(1.9)$ & $10(6.2)$ & $9(5.6)$ \\
\hline Ancylostoma sp. & $8(4.0)$ & $7(3.4)$ & $12(7.4)$ & $18(11.2)$ \\
\hline H. nana & $0(0.0)$ & $1(1.6)$ & $1(0.6)$ & $2(1.2)$ \\
\hline E. histolytica* & $12(6.0)$ & $4(1.9)$ & $16(9.8)$ & $15(9.3)$ \\
\hline Entamoeba coli* & $29(12.9)$ & $8(6.5)$ & $21(12.9)$ & $20(12.5)$ \\
\hline G. lamblia & $3(1.5)$ & $2(1.0)$ & $6(3.7)$ & $7(4.3)$ \\
\hline B. coli & $1(0.5)$ & $1(0.5)$ & $1(0.6)$ & $1(0.6)$ \\
\hline
\end{tabular}

* $\mathrm{P}<0.005$ in Kake II (experimental arm)

Table 2 shows the prevalence of different species of faecal-orally transmitted parasites in Kake II (experimental arm) and Barombi-Kang (control arm), before and after the health education intervention. In Kake II, the change in the prevalence of parasites was more significant for Ascaris lumbricoides (24.9\% vs. 
$3.4 \%, \mathrm{P}<0.001)$, Entamoeba coli $(12.9 \%$ vs. $6.5 \%$, $\mathrm{P}<0.001)$, Trichuris trichiura $(22.4 \%$ vs. $12.5 \%, \mathrm{P}=0.004)$ and Entamoeba histolytica $(6.0 \%$ vs. $1.9 \%, \mathrm{P}=0.035)$. In Barombi-Kang, there was no significant change in the prevalence of any of the faecal-orally transmitted parasites detected.

\section{DISCUSSION AND CONCLUSION}

The purpose of this study was to determine the relationship between the perception and the prevalence of faecal-oral parasite infection among school children in a rural community in Cameroon. The ten villages from which our study communities were selected are all found in the the Kumba District. The choice of this District was motivated by previous reports on high prevalence of soil transmitted infection in this area of the country $(13,14,15,18)$. The study was targeted at school children as they are mostly the heavily infected individuals in the community and are at risk of developing severe disease (11). School children are also likely to contribute to transmission and are readily accessible through the framework of school.

According to WHO (9), understanding how people regard a problem such as faecal-orally transmitted parasitic infections makes it easier to communicate with them about it. The results of this study have indicated that before health education sessions were held, only a few school children in Kake II (experimental arm) and Barombi-kang (control arm) had a good perception of faecal-orally transmitted parasite infections. Majority of children linked the infection to eating of sweet foods such as overripe fruits (mostly mangoes) and candies. The misconception of parasitic infections due to ignorance is common in most rural communities in the world, as shown by earlier reports $(19,20,21)$.

A comparison of how children perceived faecal-oral parasites; before and after health education intervention show a significant difference between the first and second phase of the study, in Kake II (experimental arm) but not in Barombi-kang (control arm). This result portraying the impact of health education on disease perception is in accordance with previous findings $(19,22)$, and proves that children who are conversant with the health knowledge of the disease are more knowledgeable of the consequences of many attitudes and practices than those who have not been exposed to such an opportunity.

Comparing the prevalence of different parasites in the experimental village where health education was implemented, there was a significant drop in Ascaris lumbricoides, Entamoeba coli, Trichuris trichuira and Entamoeba histolytica. No significant change was observed in the control arm. The significant change in prevalence observed in Kake II can not be attributed to
The relationship between the perception (knowledge of the source of infection, risk behaviour and mode of prevention and/or treatment) and the prevalence of feacal orally transmitted parasitic infections showed a strong negative correlation ( $\mathrm{r}$ dispersed between -0.97 and -99).

social or seasonal variation; the thwovillages share the same social, geographical, and climatic features. Only health education applied in the experimental village could have accounted for the observed prevalence decrease. This is in accordance with a previous study carried out in Cameroon (19) and Indian (23). Following health education, children have probably changed their sanitary behaviour and hygienic practices, adopting those which place them less at risk of becoming infected; they might have visited their local health centre for consultation and treatment. However, It can also be argued, that low infestation rate recorded during the second phase of our study in the experimental village is attributed to self-medication on the part of the children and their parents. It is possible that following health education school children developed a tendency to purchase drugs from street vendors and use them indiscriminately without medical supervision. This argument is reinforced by the fact that in Cameroon, like in many other African countries, drugs such as albendazole, Mebendazole and metronidazole can easily be purchased from street vendors at very low cost. The tendency of people to practice self medication is likely to induce long term resistance of parasites to these drugs with consequences on the transmission of these diseases (24).

There was a negative correlation between the perception and the prevalence of faecal-oral parasites in Kake II indicating that the prevalence (percentage of infected subjects) was inversely proportional to the awareness. In other words, the greater the awareness about the cause, risk behaviour and prevention/treatment of faecal-oral parasitic infections, the lower the prevalence of the disease. This can be explained by the fact that children who are conversant with the knowledge of the disease are aware of the consequences of many attitude and practices than those who have not been exposed to such opportunity. It follows that through health education, a child is exposed to health ideals which enhance the promotion of his physical, social and psychological health which ought to be pursued all through life. It is therefore important for health education to be successful, to select appropriate strategies which should address the factors contributing to behaviour that influences health (9). It is of great desire also educating mothers since their literacy will influence change in behavior of children and enhance hygienic practices. In a study on mother 
knowledge, attitudes and perception regarding intestinal parasite and diarrhoea in 3 regions of Gaza strip, Palestine, it was observed that mother's education had a positive effect for decreasing parasitosis among children (24).

This study has also shown that in rural areas, lack of adequate knowledge on faecal-orally transmitted parasitic infections improves the transmission of these

\section{REFERENCES}

1) Murray, P.R., Rosenthal, S.K., Pfaller, A.M. Medical microbiology, 5th Edition. Philadelphia: Elsevier Mosby, 2005

2) WHO. Prevention and control of schistosomiasis and soil transmitted helminthiasis. WHO Technical series Report 912, Geneva. 2002.

3) Katz, D.E., and Tayler, D.N. Parasitic infections of the gastrointestinal tract. Gastroenterol. Clin. North Am. 2001;30(3):797-815

4) Idowu, O.A. and Rowland, S.A. Oral-faecal parasites and personal hygiene of food handlers in Abeokuta, Nigeria. Afr. J. Health Sc. 2006; 6(3): 160-164

5) Assob JCN, Nde PF, Nsagha DS, Njimoh DL, Nfor $\mathrm{O}$, Njunda AL, Kamga HLF . The incidence of fecooral parasites in street-food vendors in Buea, southwest region of Cameroon. Afr. Health Sc. 2012; 12(3): 376-380

6) Stephenson, L.S., Latham, M.C., Ottessen, E.A. Malnitrition and Parasitic Helminth Infections? Parasitol. 2000; 121: 323-528

7) Hotez, P.T.. Bundy, D.A.P., Beegle, K., Brooker, S., Drake, L., De Silva, N., Savioli, L., Montressor, A., Chow, J., Bethony, J. Jukes, M. Helminth Infections: Soil Transmitted Helminth Infections and Shistosomiasis. In Jamison DT, Breman JG, Measham AR, et al., (Edn). Disease Control Priorities in Developing Countries. 2nd edition.Washington (DC): World Bank; 2006

8) Cox, F.E.G. Modern Parsitology and Helminthology. A text book of Parasitology. A Black Well Sc. pub. 1993; 6: 368-377

9) WHO. Health education in the control of parasitic diseases. 1990; W.C. 810

10) Brooker, S., Akhwale, W., Pullan, R. Epidemiology of plasmodium-helminth co-infection in Africa: Populations at risk, potential impact on anaemia, and prospects for combining control. Am. J Trop. Med. Hyg. 2007; 77: 88-98

11) Albonico, M., Crompton, D.W., Savioli, L. Control strategies for human intestinal nematode infections. Adv. Parasitol. 1999; 42: 277-341

12) Tchuem Tchuente, L.A. Polyparasitism with Schistosoma haematobium and STH infections diseases. Health education increases the knowledge and change the overall perception of the infections, and consequently the prevalence. We conclude that health education through the framework of school is an effective control method for faecal-orally transmitted parasitic infections. We recommend this inexpensive strategy to be adopted as a national policy in developing countries, as a supplement to mass distribution of drugs, especially in rural communities.

among school children in Loum, Cameroon. Trop. Med. Int. Health, 2003, 8(11):975-86.

13) Ndamukong, K.J., Ayuk M.A., Dinga, I.S., Ndiforchu, V,A, and Titanji, V.P.K. The pattern of soil transmitted nematode infection in primary school children in the Kumba health district, south west Cameroon. Af. J. Health Sc. 2000; 7(3-4):103-6

14) Nkengazong, L., Njiokou, F., Wanji, S., Teukeng, F.; Enyong, P. and Asonganyi, T. Prevalence of Soil Transmitted Helminths and Impact of Albendazole on Parasitic indices in Kotto Barombi and Marumba II villages (South West Cameroon). Afr. J. Env. Sc. Tech. 2010; 4(3): 115-121 15) Ndenecho, L., Ndamukong K.J.N., Matute, M.M. Soil Transmitted Nematodes in children in Buea Health District of Cameroon. East Afr. Med. Journ. 2002; 79

15) Ndenecho, L., Ndamukong K.J.N., Matute, M.M. Soil Transmitted Nematodes in children in Buea Health District of Cameroon. East Afr. Med. Journ, 2002; 79

16) Morrone, F.B., Carneiro, J.A., Cardozo, C.M., De Carli G.A. A study of enteroparasites infection frequency and chemotherapeutic agents used in paediatric patients in a community living in Porto Alegre, Brazil. Rev. Inst. Med. Trop. 2004; 46:77-80

17) Cheesbrough, M. District Laboratory Practice in Tropical Countries. Volume 2 Cambridge, UK. 2008; 178-235

18) Ndamukong J. K. Epidemiology of intestinal nematodes in schoolage children of Kumba health district of Cameroon. East Afr Med J 82 (11): 559-64

19) Kamga, F.H.L., Nkwelang, G., Ejezie, G.C. Health education strategy in the control of urinary shistosomiasis. J. Am. Soc. Clin. Lab. Sc. 2003; 16(3):137

20) Curtale, F., Pezzotti P., Sharbini A. L., Maadat, H. A., Ingrosso, P., Saad, Y. S. Babille. Knowledge, perceptions and behaviour of mothers toward intestinal helminths in upper Egypt: Implications for control. Health Policy Plan 1998; 13:423-432

21) Neilsen, M.; A. Hoogvorst; F. Konradsen; M. Mudasser; and W. van der Hoek. 2001. Childhood diarrhea and hygiene: Mothers' perceptions and practices in the Punjab, Pakistan: Working Paper 25. Colombo, Sri Lanka: International Water Management Institute.

22) Lansdown, R., Ledward, A., Hall, A., Issae, W., Yona, E., Matulu, J., Mweta, M., Kihamia, C., 
23) Nyandindi, U. and Bundy, D. Schistosomiasis, helminth infection and health education in Tanzania: achieving behaviour change in primary schools. Health Education Research 2008; 17: 425-433.

24) Dongre, A.R., Deshmukh, P.R., Boratne, A.V., Thaware, P., Garg, B.S. (): An approach to hygiene education among rural Indian school going children.
Online Journal of Health and Allied Sciences. 2006; 6(4): 2-8

25) Harhay, M. O., Horton, J., Olliaro, P. L. Epidemiology and control of human gastrointestinal parasites in children. Exp. Rev. Anti-Infect. Ther. 2010; 8(2): 219-234. 